\title{
REVIEW ARTICLE Preterm Birth in Low-resource Setting
}

\author{
Ali Sungkar
}

\section{Abstract}

Preterm labor (PTL) is a global problem which is a complex disease with a high rate of morbidity and mortality, also has long-term consequences for the baby and the family. The well-known morbidities related to PTL are respiratory distress syndrome, necrotizing enterocolitis, intraventricular hemorrhage, retinopathy of prematurity, and anemia of prematurity. In a developing country, the management of PTL is limited by poor health systems, low education level of the mother, poor financial support, lack of facility and trained health personnel, and demographic barriers. This limitation leads to high morbidity and mortality of preterm birth, especially in developing countries. It is important to reduce the rate of preterm birth by preventing the event. Several risk factors have been identified and are avoidable and preventable, such as smoking, bacterial infection, poor nutritional status, and malnourished mothers. Strategies to prevent PTL have been proposed in primary, secondary, and tertiary interventions to reduce the morbidity and mortality of preterm birth.

Keywords: Management, Morbidity and mortality, Preterm labor, Risk factor.

Donald School Journal of Ultrasound in Obstetrics and Gynecology (2021): 10.5005/jp-journals-10009-1695

\section{INTRODUCTION}

Preterm labor (PTL) is birth at or after 20 weeks but before 37 completed week's gestation. ${ }^{1,2}$ The WHO defines preterm birth as any birth before 37 completed weeks of gestation, or fewer than 259 days since the first day of the woman's last menstrual period (LMP) and this can be further subdivided based on gestational age: extremely preterm ( $<28$ weeks), very preterm ( $28-32$ weeks), and moderate or late preterm (32-36 weeks of gestation). ${ }^{3}$ Preterm labor is included in the term "The Great Obstetrical Syndrome" defined by Roberto Romero. As PTL or birth is caused by multiple etiologies. ${ }^{3,4}$

Preterm can be classified into three groups by the process preceding the labor: spontaneous preterm birth, preterm premature rupture of membrane, and provider-initiated preterm birth (defined as the induction of labor or elective cesarean section before 37 completed weeks of gestation due to maternal or fetal indications). Morbidity by provider-initiated preterm birth is increasing in many high-income and middle-income countries. ${ }^{3}$ Preterm birth is a complex disease with a high rate of morbidity and mortality of newborns worldwide. The wellknown morbidities of preterm delivery are respiratory distress syndrome, necrotizing enterocolitis, intraventricular hemorrhage, retinopathy of prematurity, anemia of prematurity, and they have their long-term consequences for both the neonates and the parents. ${ }^{2,4}$

The incidence of preterm birth varies between $5 \%$ and $18 \%$ of all births and is increasing. ${ }^{2,5}$ In 2010, an estimated 14.9 million babies (12.3-18.1 million) were born preterm, $11.1 \%$ of all live births worldwide, ranging from about $5 \%$ in several European countries to $18 \%$ in some African countries. ${ }^{5}$ More than $60 \%$ of preterm babies were born in South Asia and sub-Saharan Africa, where $52 \%$ of the global live births occur. ${ }^{3}$ Indonesia contributed for 675,700 cases with an incidence rate of 15.5 per 100 live births in $2010 .{ }^{6}$ In Cipto Mangunkusumo Hospital Jakarta, data of July 2007 to December 2009 showed that there were $55.4 \%$ of preterm birth.
Fetomaternal Division, Department of Obstetrics and Gynecology, Faculty of Medicine, University of Indonesia, Jakarta, Indonesia; Cipto Mangunkusumo National Hospital, Jakarta, Indonesia

Corresponding Author: Ali Sungkar, Fetomaternal Division, Department of Obstetrics and Gynecology, Faculty of Medicine University of Indonesia, Jakarta, Indonesia; Cipto Mangunkusumo National Hospital, Jakarta, Indonesia, Phone: +628129312548, e-mail: alisungkar@yahoo.com

How to cite this article: Sungkar A. Preterm Birth in Low-resource Setting. Donald School J Ultrasound Obstet Gynecol 2021;15(2): 175-178.

Source of support: Nil

Conflict of interest: None

\section{RisK Factors}

About two-thirds of preterm births are spontaneous. ${ }^{3}$ Preterm labor is abnormal signaling and activation of one or more common pathways of labor. ${ }^{1}$ Many factors contribute to the spontaneous preterm birth process. Several pathological processes related to PTL have been identified, such as intrauterine infection or inflammation, uterine ischemia, uterine overdistension, abnormal allograft reaction, allergy, cervical insufficiency, and hormonal disorder. ${ }^{1,7}$ In up to half of all cases, the precise etiologies are unidentified. Assisted reproductive techniques and the concomitant increase in multiple pregnancies have contributed to the rise. ${ }^{5,8}$ Nearly $60 \%$ of twins and nearly all triplet and higher-order multiple births will be born preterm. ${ }^{9,10}$ Surgical intervention for the management of cervical intraepithelial neoplasia (such as loop excision of the cervical transformation zone) is associated with a two-fold increase in the risk of preterm birth. ${ }^{3,11}$ Individual or family history of preterm birth, young or advanced maternal age, short interpregnancy intervals, low maternal body mass index (BMI), multiple pregnancy, preexisting noncommunicable disease, hypertensive disease of pregnancy, and infections are risk factors for preterm birth ${ }^{3,12,13}$ The cause of preterm birth is multifactorial, with social, psychological, 
and biological factors playing a role. ${ }^{14}$ The etiologies differ according to gestational age, ethnicity, and characteristics unique to each population. ${ }^{15}$

\section{Problems of Management in Developing Countries}

Developing countries like Indonesia lack facilities contributing to higher morbidity and mortality of mothers and children. Poor health systems, low education level of the mother, poor financial support, lack of facility and trained health personnel, and demographic barriers are important factors contributing to the higher rate of mortality and morbidity for mothers and children. ${ }^{16}$ There are three types of delays in obstetric and neonatal care. ${ }^{17}$ Delay of recognition and decision to seek care, delay of transport to care, and delay of receiving the quality of care. Programs that have been established to reduce the number are increasing skilled attendance, developing the quality of maternal and neonatal care, antenatal risk screening, educating the community about pregnancy and birth, and improving the referral and transportation system. Interventions to reduce the morbidity and mortality related to preterm birth can be classified as primary (directed to all women before or during pregnancy to prevent and reduce risk), secondary (aimed at eliminating or reducing risk in women with known risk factors), or tertiary (initiated after the parturition process has begun, to prevent a delivery or improve outcomes for preterm infants). ${ }^{2,17}$

\section{Prevention}

Primary prevention is the strategy directed at all women before or during pregnancy to reduce the risk of preterm birth. Primary interventions are beneficial to the overall health of the woman as they include weight optimization, nutritional supplementation, smoking cessation, and avoidance of late-preterm births. ${ }^{14}$

The prepregnancy BMI is useful clinically for evaluating the nutritional status and a low BMI is considered a strong predictor of adverse pregnancy outcomes such as PTB. ${ }^{13}$ Women with BMI $<19 \mathrm{~kg} / \mathrm{m}^{2}$ have the greatest risk of PTB compared to women with $\mathrm{BMI}>30 \mathrm{~kg} / \mathrm{m}^{2}$. Therefore, nutritional and lifestyle adjustment to ensure that weight is within the normal range is recommended in the preconception period. ${ }^{13}$ Many researchers found that mothers with a low prepregnancy BMI had an increased risk for preterm and very preterm birth. Women with a low prepregnancy BMI who maintained a moderate level of gestational weight gain (0.23-0.68 $\mathrm{kg} /$ week) had a reduced risk for preterm and very preterm birth.

There are two important potential mechanisms by which low prepregnancy BMI may contribute to preterm: maternal undernutrition, infection, and inflammation. ${ }^{14}$ Low prepregnancy BMI may be an indication of chronic nutritional deficiency (macronutrients and micronutrients), which may negatively impact normal processes of fetal growth and development, leading to adverse outcomes such as preterm birth obesity. ${ }^{18}$ Obese women have higher rates of delivery due to preeclampsia and gestational diabetes, and also have higher rates of congenital anomalies. ${ }^{19}$

Low serum levels of micronutrients such as iron, folate, and zinc are highly prevalent among pregnant women in low-income settings and are associated with preterm birth and stillbirth. The role of nutritional supplementation in this setting is controversial, with numerous studies reporting conflicting results. ${ }^{14}$

One hypothesis is that maternal hyperhomocysteinemia has a role in the origin of preterm birth and the reduced maternal folate status associates with elevated homocysteine-related placental vasculopathy. This can be neutralized with a high dose of folic acid supplementation during pregnancy particularly in the third trimester, the high dose of folic acid supplementation during pregnancy particularly in the third trimester reduces the risk of preterm birth. ${ }^{20}$ Although the effect of preconception zinc supplementation on preterm birth has not been studied, a Cochrane review of zinc supplementation initiated before 27 weeks of gestation has shown a small but significant reduction in preterm birth (relative risk 0.86). ${ }^{19}$

Cigarette smoking is a well-known cause of both preterm birth and intrauterine growth restriction. The risk attributable to cigarette smoking is $>25 \%$ for preterm birth and is about $5 \%$ for infant mortality. ${ }^{14}$

Control of the prepregnancy metabolic disease is needed to decrease the rate of preterm birth. Suboptimal control of hypertension in early pregnancy in women with diabetic nephropathy is associated with a significant risk of preterm delivery. Improved preconception control of hypertension may reduce adverse perinatal outcomes in women with diabetic nephropathy. ${ }^{21}$

Early detection and therapy of vaginal infection is thought to reduce the incidence of preterm birth. A cohort study in AfroAmerican women showed that vaginal douching effects on the risk of preterm birth depend on the timing of the exposure. They concluded that douching in the 6 months before pregnancy, but not during pregnancy, appears to protect against preterm birth. ${ }^{20}$

Increased awareness of PTB as the leading cause of infant mortality might offer an opportunity to inform the public and the medical profession about potentially avoidable risk factors such as abnormal weight, smoking, poor nutrition, and repeated uterine instrumentation. Choices made in the fertility care such as the number of embryos transferred might be affected by broader public knowledge of the significantly increased risk of preterm birth in multiple gestations conceived with assisted reproductive technology. ${ }^{14}$

\section{Early Detection}

The methods for early detection of women with high-risk preterm birth include transvaginal ultrasound and fetal fibronectin. ${ }^{22-24}$ In a limited source health facility, fetal fibronectin is not available. Transvaginal ultrasound is a reliable examination for the detection of preterm birth. ${ }^{25}$ Transvaginal ultrasound which measuring cervical length and funneling is safe, acceptable, and reproducible. ${ }^{22,23}$

\section{Preconceptional Primary Prevention}

Preconception care has a benefit to maternal, fetal, and neonatal outcomes. It also has an impact to decrease the rate of PTL. ${ }^{26}$ Preconception point emphasize on promoting healthy lifestyle interfering fertility on the period and between pregnancies. ${ }^{26}$ Tobacco smoking during pregnancy will increase adverse pregnancy outcomes including PTL. ${ }^{27}$ Prepregnancy weight has an impact on pregnancy outcome. Underweight women and obese women have an increased risk of adverse pregnancy outcome compared to normal body weight women. ${ }^{19,23,28}$

\section{Public Educational Interventions}

Preterm labor information is promoted by giving information about risk factors and the impact of PTL during preconception care in public health service and religious institutions for a young couple and married couple. ${ }^{28}$ It could increase awareness of PTL as the 
leading cause of infant morbidity and mortality by preventing and avoiding risk factors.

\section{Raise Awareness of Scope and Significance of Preterm Labor}

Awareness of PTL includes the awareness of the short-term and long-term impact of PTL to baby and the family by education about PTL and its risk factors such as unplanned pregnancy, pregnancy at extremes age, interpregnancy interval (18-24 months), substance abuse, and sexually transmitted disease. ${ }^{28}$

\section{Public and Professional Policies}

A health policy adopted by the government to improve availability and utilization of reliable and acceptable contraception, minimal uterine instrumentation, protection in the working environment (increased salary for pregnant women, exemption from night shift, working time limitation), and limit number of embryos transferred during IVF will decrease the rate of PTL. ${ }^{28}$

\section{Preconceptional Management}

Education about risk factors, signs, symptoms, and outcomes of PTL. Preparation of maternal and baby health insurance. ${ }^{28}$

\section{Risk Factor Reduction ${ }^{28-30}$}

Several actions that could prevent PTL are:

- Gynecology examination: ultrasound examination, Pap smear, early detection, and management of genital infection.

- Detection of asymptomatic bacteriuria.

- Management of metabolic disease/comorbidity.

- Nutritional supplements.

- Smoking cessation.

\section{Early Detection and Prompt Intervention}

Risk factors include prior preterm birth, multiple gestations, uterine anomalies, the prior or current risk of preeclampsia, IUGR, birth defects, medical disease, vaginal discharge, substance abuse, abnormal BMI, and pregnancy in the extreme ages need to be screened early. ${ }^{28,31}$ Screening that could be performed during antenatal care is a vaginal examination in the first antenatal care, urine examination, nutritional supplements during pregnancy, and smoking cessation in pregnancy. ${ }^{32,33}$

Based on the meta-analysis that the risk of preterm birth doubled when bacterial vaginosis was diagnosed before 20 weeks of pregnancy. Sungkar et al. made a multicenter RCT on pregnant women across Jakarta and Cipto Mangunkusumo National Central Hospital. ${ }^{31}$ Scoring system was made and concluded history of preterm birth, cigarette smoking, history of abortion, yellowish vaginal discharge, and tooth-related complaints during pregnancy as the variables. ${ }^{4}$

This paper was previously published in Chervenak FA, Kupesic Plavsic S, Kurjak A. The Fetus as a Patient: Current Perspectives. New Delhi: Jaypee Brothers Medical Publishers; 2020. pp. 281-286.

\section{References}

1. Romero R, Espinoza J, Kusanovic J, et al. The preterm parturition syndrome. BJOG 2006;113(Suppl 3):17-42. DOI: 10.1111/j.14710528.2006.01120.x.

2. Requejo $\mathrm{JH}$, Merialdi $M$. The global impact of preterm birth. In: Berghella V, ed. Preterm birth prevention and management. West Sussex: Blackwell Publishing; 2010. p. 1-7.
3. Blencowe $\mathrm{H}$, Cousens $\mathrm{S}$, Oestergaard $\mathrm{MZ}$, et al. National, regional, and worldwide estimates of preterm birth rates in the year 2010 with time trends since 1990 for selected countries: a systematic analysis and implications. Lancet 2012;379(9832):2162-2172. DOI: 10.1016/ S0140-6736(12)60820-4.

4. Treyvaud K. Parent and family outcomes following very preterm or very low birth weight birth: a review. Semin Fetal Neonat Med 2014;19(2):131-135. DOI: 10.1016/j.siny.2013.10.008.

5. Hansen $M$, Bower $C$. The impact of assisted reproductive technologies on intra-uterine growth and birth defects in singletons. Semin Fetal Neonatal Med 2014;19(4):228-233. DOI: 10.1016/j.siny.2014. 03.002.

6. March of Dimes, PMNCH, Save the Children, WHO. Born too soon: the global action report on preterm birth. Geneva: 2012.

7. Romero R, Dey SK, Fisher SJ. Preterm labor: one syndrome, many causes. Science 2014;345(6198):760-765. DOI: 10.1126/ science.1251816.

8. Tallandini MA, Morsan V, Macagno F. Preterm birth and assisted reproductive technology/ART: maternal emotional wellbeing and quality of mother-newborn interaction during the first three months of life. Early Hum Dev 2012;88(6):397-402. DOI: 10.1016/j. earlhumdev.2011.10.003.

9. Beer C, Israel C, Johnson S, et al. Twin birth: an additional risk factor for poorer quality maternal interactions with very preterm infants? Early Hum Dev 2013;89(8):555-559. DOI: 10.1016/j.earlhumdev.2013.02.006.

10. Brubaker SG, Gyamfi C. Prediction and prevention of spontaneous preterm birth in twin gestations. Semin Perinatol 2012;36(3):190-194. DOI: 10.1053/j.semperi.2012.02.003.

11. Miller ES, Grobman WA. The association between cervical excisional procedures, midtrimester cervical length, and preterm birth. Am J Obstet Gynecol 2014;211(3):242.e1-e4. DOI: 10.1016/j. ajog.2014.03.004.

12. Almario CV, Seligman NS, Dysart KC, et al. Risk factors for preterm birth among opiate-addicted gravid women in a methadone treatment program. Am J Obstet Gynecol 2009;201(3):326.e1-e6. DOI: 10.1016/j. ajog.2009.05.052.

13. Been JV, Lievense S, Zimmermann LJ, et al. Chorioamnionitis as a risk factor for necrotizing enterocolitis: a systematic review and meta-analysis. J Pediatr 2013;162(2):236-42.e2. DOI: 10.1016/j. jpeds.2012.07.012.

14. Flood K, Malone FD. Prevention of preterm birth. Semin Fetal Neonat Med 2012;17(1):58-63. DOI: 10.1016/j.siny.2011.08.001.

15. Murphy DJ. Epidemiology and environmental factors in preterm labour. Best Pract Res Clin Obstet Gynaecol 2007;21(5):773-789. DOI: 10.1016/j.bpobgyn.2007.03.001.

16. Shah R, Mullany LC, Darmstadt GL, et al. Incidence and risk factors of preterm birth in a rural Bangladeshi cohort. BMC Pediatr 2014;14(1):112. DOI: 10.1186/1471-2431-14-112.

17. Nour NM. An introduction to maternal mortality. Rev Obstet Gynecol 2008;1(2):77-81.

18. Salihu HM, Mbah AK, Alio AP, et al. Low pre-pregnancy body mass index and risk of medically indicated versus spontaneous preterm singleton birth. Eur J Obstet Gynecol Reprod Biol 2009;144(2):119-123. DOI: 10.1016/j.ejogrb.2009.02.047.

19. Stock SJ, Oyston C, Norman JE. Management of a woman with a previous preterm birth. Obstet, Gynaecol Reprod Med 2013;23(2):5358. DOI: 10.1016/j.ogrm.2013.01.001.

20. Czeizel AE, Puho EH, Langmar Z, et al. Possible association of folic acid supplementation during pregnancy with reduction of preterm birth: a population-based study. Eur J Obstet Gynecol Reprod Biol 2010;148(2):135-140. DOI: 10.1016/j.ejogrb.2009.10.016.

21. Carr D, Koontz G, Gardella C, et al. Diabetic nephropathy in pregnancy: suboptimal hypertensive control associated with preterm delivery. Am J Hypertens 2006;19(5):513-519. DOI: 10.1016/j. amjhyper.2005.12.010.

22. Chatterjee J, Gullam J, Vatish M, et al. The management of preterm labour. Arch Dis Child Fetal Neonatal Ed 2007;92(2):F88-F93. DOI: 10.1136/adc.2005.082289. 
23. Hamilton SA, Tower CL. Management of preterm labour. Obstet, Gynaecol Reproduc Med 2010;20(8):235-240. DOI: 10.1016/j. ogrm.2010.04.007.

24. DeFranco EA, Lewis DF, Odibo AO. Improving the screening accuracy for preterm labor: is the combination of fetal fibronectin and cervical length in symptomatic patients a useful predictor of preterm birth? a systematic review. Am J Obstet Gynecol 2013;208(3):233.e1-e6. DOI: 10.1016/j.ajog.2012.12.015.

25. Salomon LJ, Diaz-Garcia C, Bernard JP, et al. Reference range for cervical length throughout pregnancy: non-parametric LMS-based model applied to a large sample. Ultrasound Obstet Gynecol 2009;33(4):459-464. DOI: 10.1002/uog.6332.

26. Hurst HM, Linton DM. Preconception care: planning for the future. J Nurse Practition 2015;11(3):335-340. DOI: 10.1016/j. nurpra.2014.09.011.

27. Ko T-J, Tsai L-Y, Chu L-C, et al. Parental smoking during pregnancy and its association with low birth weight, small for gestational age, and preterm birth offspring: a birth cohort study. Pediatr Neonatol 2014;55(1):20-27. DOI: 10.1016/j.pedneo.2013.05.005.
28. lams JD, Romero R, Culhane JF, et al. Primary, secondary, and tertiary interventions to reduce the morbidity and mortality of preterm birth. Lancet 2008;371(9607):164-175. DOI: 10.1016/S0140-6736(08)60108-7.

29. Zhou Q, Zhang W, Xu H, et al. Risk factors for preterm premature rupture of membranes in Chinese women from urban cities. Int J Gynaecol Obstet 2014;127(3):254-259. DOI: 10.1016/j.ijgo.2014.06.020.

30. Danhof NA, Kamphuis El, Limpens J, et al. The risk of preterm birth of treated versus untreated cervical intraepithelial neoplasia (CIN): a systematic review and meta-analysis. Eur J Obstet Gynecol Reproduct Biol 2015;188(0):24-33. DOI: 10.1016/j.ejogrb.2015.02.033.

31. Sungkar A, Purwosunu Y, Aziz MF, et al. Influence of early selfdiagnosis and treatment of bacterial vaginosis on preterm birth rate. Int J Gynaecol Obstet 2012;117(3):264-267. DOI: 10.1016/j. ijgo.2012.01.007.

32. Romero R. Spontaneous preterm labor can be predicted and prevented. Ultrasound Obs Gyn 2021;57(1):19-21. DOI: 10.1002/ uog. 23565.

33. Goldenberg R, Culhane J, lams J, et al. Epidemiology and causes of preterm birth. Lancet 2008;371(9606):75-84. DOI: 10.1016/S01406736(08)60074-4. 